\title{
THE EFFECTS OF ZnO NANOPARTICLES IN COMBINATION WITH ALCOHOL ON BIOSYNTHETIC POTENTIAL OF SACCHAROMYCES CEREVISIAE
}

\author{
- Research paper - \\ Natalia CHISELIŢA ${ }^{1}$, Agafia USATII, Nadejda EFREMOVA \\ Institute of Microbiology and Biotechnology of Academy of Sciences of Moldova, Academiei \\ Street 1, MD-2028 Chişinău, Moldova
}

\begin{abstract}
This paper reports about experimental results concerning the influence of $30 \mathrm{~nm} \mathrm{ZnO}$ nanoparticles on biomass, carbohydrates, $\beta$-glucans, proteins accumulation and catalase enzyme activity at Saccharomyces cerevisiae CNMN-Y-20 yeast strain exposed to alcohol action. Alcohol in concentrations of 2\%, 5\% and 10\% added to culture medium has been reported to stimulate $\beta$-glucans biosynthesis and to inhibit protein synthesis. Low biomass production, with $71 \%$ less that control, was detected in the experiments with $10 \%$ alcohol. $\mathrm{ZnO}$ nanoparticles in combination with alcohol do not offer sufficient protection for the proteins biosynthesis, but efficiently protect the carbohydrates and $\beta$-glucans biosynthetic processes, which contents in the biomass are with $16.6 \%$ and $19.9 \%$ higher than control, respectively. The maximum value of $\beta$-glucans content was established in case of cultivation of selected yeast strain on YPD medium supplemented with $5 \mathrm{mg} / \mathrm{L}$ nanoparticles $\mathrm{ZnO}$ and $2 \%$ alcohol. The obtained results allowed the elaboration of new procedure for directed synthesis of $\beta$-glucans that contributed to an increase of this component with 30.7\%, compared to control.
\end{abstract}

Key words: Saccharomyces cerevisiae, nanoparticles, alcohol, biomass production, carbohydrates, $\beta$-glucans, proteins, catalase activity.

\section{INTRODUCTION}

Nowadays, the influence of nanoparticles on different biological objects, inclusive microorganisms, is of great scientific interest (Espitia et al., 2012; Egorova et al., 2016). The study of the impact of different nanoparticles on growth, development and enzymatic activity of micromycetes (Sîrbu et al., 2015), bacteria (Santimano et al., 2013), biosynthetic potential and enzymatic activity of yeasts (Padroval et al., 2016) has demonstrated different effects depending on the nanoparticles structure and biotechnological object.

Inorganic compounds with nanodimensions possess high activity in low concentrations due to the large area of ratio the surface to volume and unique physical and chemical properties (Rai et al., 2009). Nanoparticles also demonstrate high stability in extreme conditions such as high temperature and pressure (Sawai, 2003). Some nanoparticles are non-toxic and contain essential mineral elements for human organism (Roselli et al.,
2003). Recent studies offer perspective on the potential of $\mathrm{ZnO}$ nanoparticles utilization as supplement in order to increase active production of $\beta$-glucosidase - enzyme of $S$. cerevisiae with industrial value, as well as to increase production of baker's yeast (Ban et al., 2014).

Saccharomyces cerevisiae yeasts and their metabolites inclusive components of cellular wall are considered as safe materials by US Food and Drug Administration (FDA, 1997) and could be used legally as food ingredients and food supplements (Kwiatkowski et al., 2012). $\beta$-glucans obtained from yeasts serve as components of industrial bioproducts such as BetaRight ${ }^{\circledR}$ and WGP ${ }^{\circledR}$ (Biotheras, Inc.) proposed for application as ingredients of baking, drinks, yogurts, juice, chocolate and thickening agents for salad dressing, ice cream, mayonnaise, sauces and cheeses (Zechner et al, 2009).

The search of the new ways for development of microbial innovative biotechnologies has a great importance. Currently, the possibility to stimulate metabolic processes at yeasts by the

${ }^{1}$ Corresponding author. E-Mail address: chiselita.natalia@gmail.com 
application of nanoparticles is insufficiently studied. The research carried out on some yeast strains have demonstrated contradictory results. Given the fact, that products obtained from yeasts are inoffensive for human organism and perspective of nanomaterials utilization in different areas, the study of metal oxide nanoparticles influence on biosynthetic potential of Saccharomyces cerevisiae yeast strain are of scientific interest. The results of the following study can serve for elaboration of some efficient procedures for obtaining of biomass with predictable biochemical content. Biochemical composition of yeasts could be regulated by the variation of cultivation

\section{MATERIALS AND METHODS}

Object of study. Yeast strain Saccharomyces cerevisiae CNMN-Y-20 from Collection of Yeasts Biotechnology Laboratory and the Collection of Nonpathogenic Microorganisms of the Institute of Microbiology and Biotechnology of Academy of Sciences of Moldova producer was used in this study; the yeast strain is a $\beta$-glucans producer (Chiseliţa et al., 2010).

$\mathrm{ZnO}$ nanoparticles (NPs) with dimension of 30 $\mathrm{nm}$, stabilized in polyvinylpyrrolidone (PVP) were offered by researchers of the Institute of Electronic Engineering and Nanotechnologies "D. Ghitu" of Academy of Sciences of Moldova (Guţul et al., 2014). The NPs concentrations used in the cultivation of yeasts were 5,10 and $15 \mathrm{mg} / \mathrm{L}$. Ethyl alcohol was added to culture medium in volumes of $2 \%$, $5 \%$ and $10 \%$. The sample without nanoparticles and alcohol served as control.

Culture medium and cultivation conditions. Fermentation medium YPD and beer wort were used for the inoculation and submerged cultivation of yeasts (Agiular et al., 2003). The submerged cultivation was effectuated in Erlenmeyer flasks with capacity $1 \mathrm{~L}$ on shaker

\section{RESULTS AND DISCSSIONS}

The results demonstrate significant modifications of cellular components content at the cultivation of Saccharomyces cerevisiae CNMN-Y-20 strain using YPD medium supplemented with $2 \%, 5 \%$ and $10 \%$ alcohol. Thus, alcohol added in selected concentrations demonstrates beneficial effect on $\beta$-glucans conditions, as well as by the utilization of some stimulators. The adaptive cell response varied depending on strain. Accordingly, on the first stage of the study, the influence of alcohol that can be accumulated in large amount during industrial fermentation and deviated biosynthetic activity of yeasts is studied in this research. Further, experiments for monitoring cellular adaptive response at the cultivation in presence of $\mathrm{ZnO}$ nanoparticles in combination with alcohol are carried out to determinate the possibility for neutralization of toxic effects of alcohol on yeasts metabolism applied in high concentrations.

with $200 \mathrm{rpm}$ rotation speed at the temperature $25^{\circ} \mathrm{C}$, aeration rate $81.3 \ldots 83.3 \mathrm{mg} / \mathrm{L}$. The duration of cultivation was 120 hours. The volume of inoculated yeasts cells constituted $5 \%\left(2 \times 10^{6}\right.$ cells $\left./ \mathrm{ml}\right)$.

Research methods. Yeasts biomass was determined gravimetrically (Hong-Zhi et al., 2009). The carbohydrates content in the yeasts biomass was determined spectrophotometrically at $620 \mathrm{~nm}$ wavelength using antron reagent and D-glucose as standard (Dey et al., 1993) by using a PG T60 VIS spectrophotometer. The $\beta$-glucans content in the yeasts biomass was quantified gravimetrically as described (Thammakiti et al., 2004). Protein was determined by Lowry method (Lowry et al., 1951) using bovine serum albumin as standard. Catalase activity was determined by the method described in (Aebi, 1984, Efremova et al., 2012).

Statistical processing of results was carried out using statistical software kit 7. Statistical processing of obtained results was effectuated electronically with the calculation of the standard errors for the relative and average values, the differences between the experimental and control data were established using Student's t-test and $\mathrm{P}$ value.

biosynthesis, their content was increased by 10-13\% compared to control (Figure 1). Even so, response reaction of yeasts to alcohol presence in $10 \%$ concentration is manifested by the significant decrease of biomass content to $1.55 \mathrm{~g} / \mathrm{L}$ that is with $71 \%$ less than control. It is necessary to mention that protein content is decreased, also, in limits of $10-15 \%$ at the application of alcohol in 2, 5 and $10 \%$ 
concentrations. The same inhibiting effect of alcohol is observed in the case of determination of catalase activity, antioxidant enzyme. However, catalase activity is increased at the use of $10 \%$ alcohol that served as toxicity index (Figure 1).

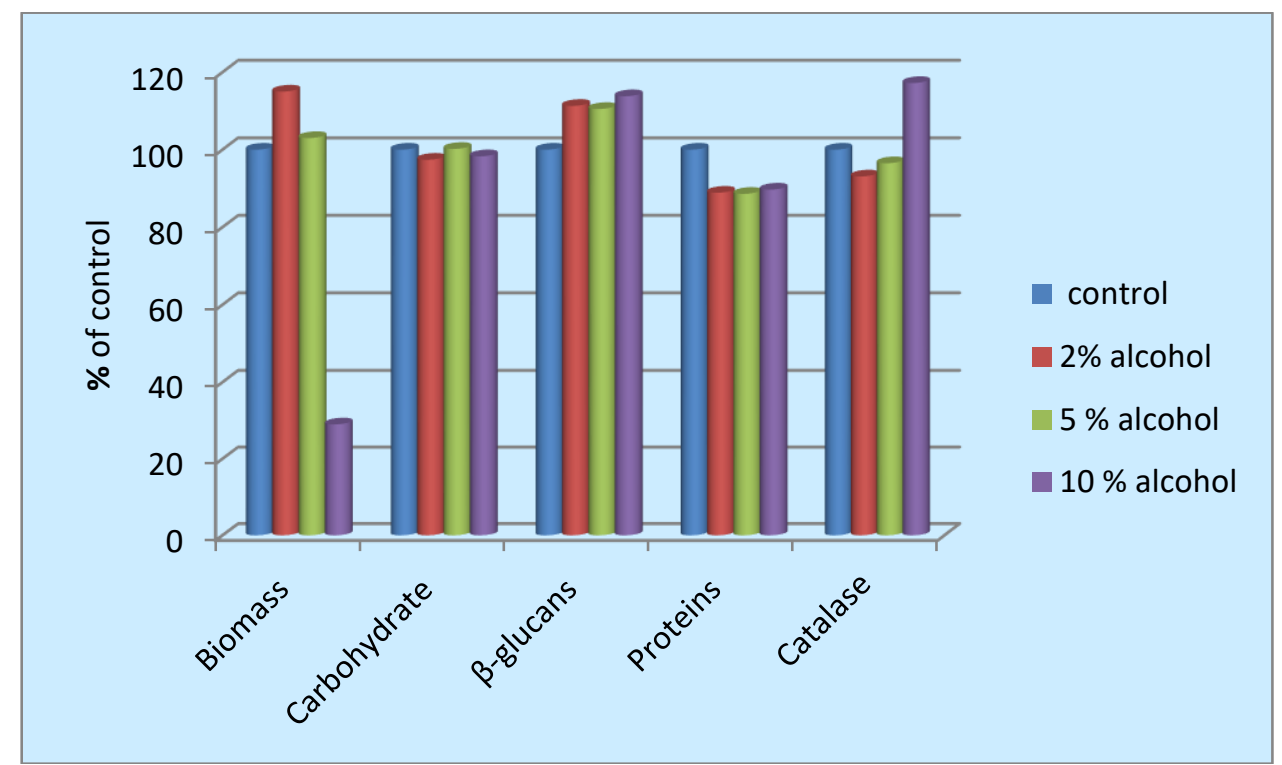

Figure 1. The degree of modification of the bioactive principles content at the cultivation of Saccharomyces cerevisiae CNMN-Y-20 yeast strain under the influence of alcohol, \% of control.

Therefore, on the base of obtained experimental results it can be mentioned that the combination of $5 \%$ alcohol with $10 \mathrm{mg} / \mathrm{L}$ and $15 \mathrm{mg} / \mathrm{L}$ of $\mathrm{ZnO}$ nanoparticles contributed to decrease of cell multiplication, thus, biomass content after 120 hours of submerged cultivation on YPD medium was less with 14$18 \%$ compared to control (Figure 2). The

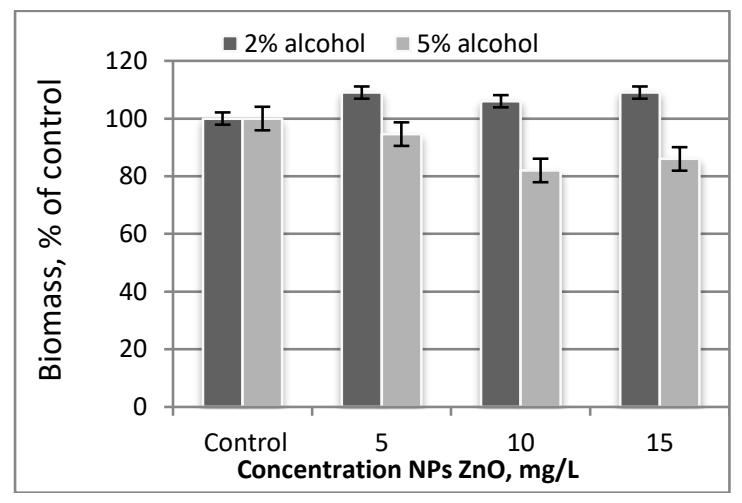

quantitative determination of the proteins in Saccharomyces cerevisiae CNMN-Y-20 biomass reveals the fact that $\mathrm{ZnO}$ nanoparticles applied in combination with $2 \%$ alcohol do not modifies significantly the content of these. The protein content is decreased with 4-7\% comparative to control in experimental variants alcohol $+\mathrm{ZnO}$ nanoparticles.

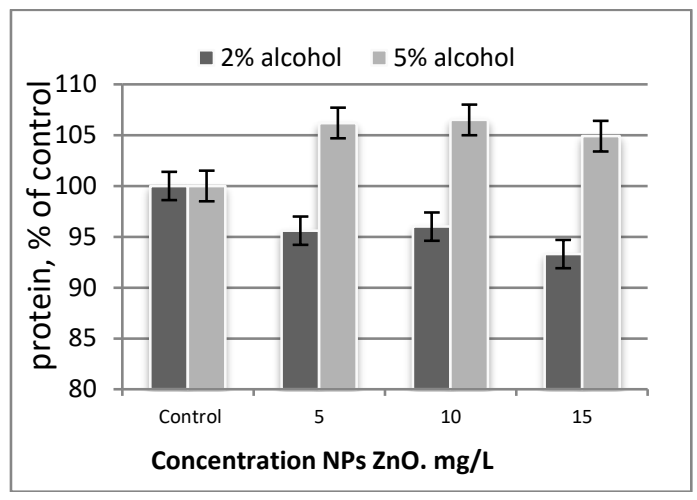

Figure 2. Effects of $30 \mathrm{~nm} \mathrm{ZnO}$ nanoparticles in combination with alcohol etilic on biomass and protein content at Saccharomyces cerevisiae CNMN-Y-20

At the same time, results of the influence of $\mathrm{ZnO}$ nanoaprticles added in combination with higher alcohol concentration of nutrient substrate $(5 \%$ alcohol) indicates another effect on protein content compared to combination of $2 \%$ alcohol with $\mathrm{ZnO}$ nanoparticles in 5, 10, 15 $\mathrm{mg} / \mathrm{L}$. Thus, increasing of the concentration of alcohol up to $5 \%$ in combination with nanoparticles contributes to the insignificant increase of protein content with 4-5\% compared to control (Figure 2). Therefore, the analysis and interpretation of experimental results regarding the protein content at presence of alcohol and $\mathrm{ZnO}$ nanoparticles has demonstrates that $\mathrm{ZnO}$ nanoparticles partly neutralize the harmful effect of alcohol on the 
process of proteins biosynthesis. In this case, the effect of nanoparticles can be explained by the possible involvement of $\mathrm{Zn}$ ions in biosynthetic processes and processes of regeneration of cell membrane via enzymes catalysing these processes.

Concerning the carbohydrates and $\beta$-glucans content in yeasts biomass, it was determined that combination alcohol - $\mathrm{ZnO}$ nanoparticles caused activation of biosynthetic processes. The obtained results indicate the cumulative positive effect of these two factors of cultivation on studied parameters. The content of carbohydrates and $\beta$-glucans increases depending on concentration with $10.7-16.6 \%$ and 12.1-19.9\% compared to control, respectively (Figure 3). The maximal stimulatory effect relative to $\beta$-glucans content is detected at the use of combination of $2 \%$ alcohol+5 $\mathrm{mg} / \mathrm{L} \quad \mathrm{ZnO}$ nanoparticles.
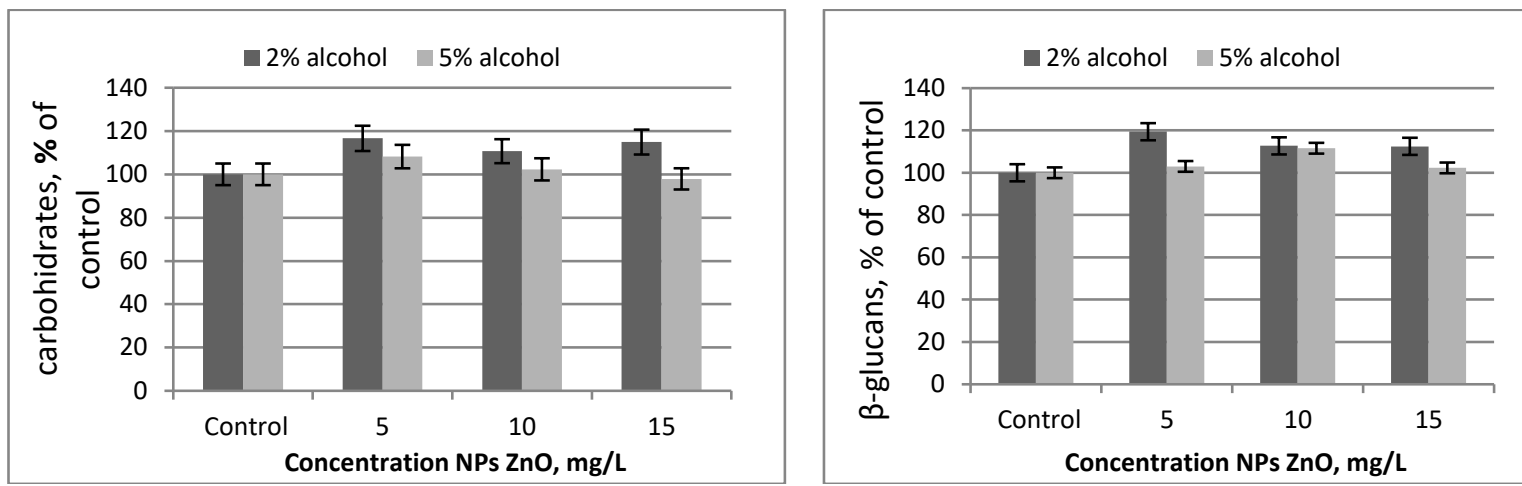

Figure 3. Effects of $30 \mathrm{~nm} \mathrm{ZnO} \mathrm{nanoparticles} \mathrm{în} \mathrm{combination} \mathrm{with} \mathrm{alcohol} \mathrm{on} \mathrm{carbohydrates} \mathrm{and} \beta$ glucans content at Saccharomyces cerevisiae CNMN-Y-20

Antioxidant enzyme activity levels have a great importance for toxicity level determination. The cumulative results were obtained at the determination of catalase activity at the cultivation of yeasts in presence of $\mathrm{ZnO}$ nanoparticles in combination with alcohol. Catalase activity varied insignificantly depending on concentration of nanoparticles used at cultivation of yeast strain (Figure 4). Thus, catalase activity increases with $10-16 \%$ compared to control at the highest concentration of nanoparticles $-15 \mathrm{mg} / \mathrm{L}$.

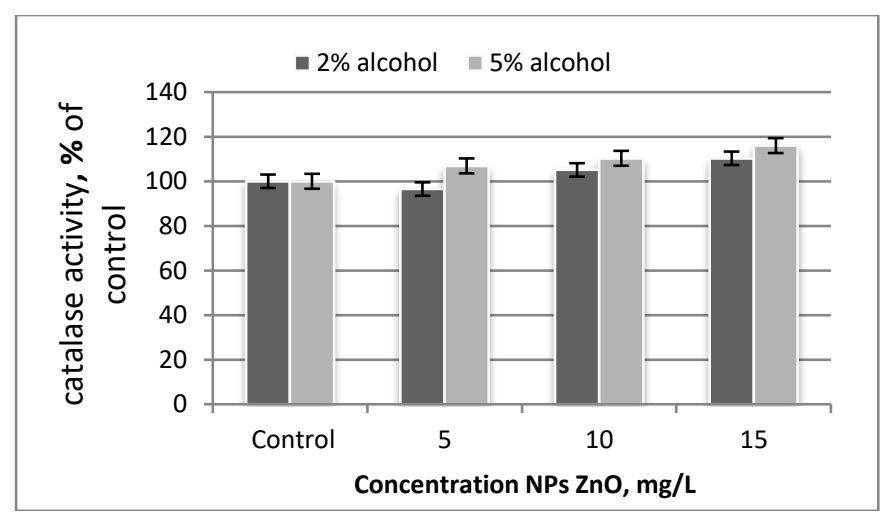

Figure 4. Catalase activity in Saccharomyces cerevisiae CNMN-Y-20 biomass at the cultivation in presence of $30 \mathrm{mn} \mathrm{ZnO}$ nanoparticles in combination with alcohol

Taking into consideration that administration of $\mathrm{ZnO}$ nanoparticles in combination with alcohol has benefited action on $\beta$-glucans values at yeast strain, the comparative analysis of growth rate of cellular biomass and $\beta$ glucans content was carried out. The results demonstrated that specific growth rate of yeasts is maximal (6.02-6.16 g/L dry biomass) at the cultivation in presence of $\mathrm{ZnO}$ nanoparticles compared to other experimental samples. Minimal growth rate $(1.55 \mathrm{~g} / \mathrm{L}$ dry biomass) was determined at the cultivation in presence of $10 \%$ alcohol (table 1). In the case of determination of $\beta$-glucans content, the 
highest values $(21.25 \%-22.55 \%)$ are obtained at the cultivation on substrate supplemented with $2 \%$ alcohol and $\mathrm{ZnO}$ nanoparticles. while values of $\beta$-glucans in control sample constituted 18.85. The level of the $\beta$-glucans production in experimental variants varies from $0.32 \mathrm{~g} / \mathrm{L}$ to $1.32 \mathrm{~g} / \mathrm{L}$ with the maximal values at $2 \%$ alcohol and $5 \mathrm{mg} / \mathrm{L} \mathrm{ZnO}$ nanoparticles in culture medium (Table 1).

Table 1. The rate of biomass and $\beta$-glucans values at Saccharomyces cerevisiae CNMN-Y-20 at the cultivation on YPD medium in presence of $\mathrm{ZnO}$ nanoparticles and alcohol

\begin{tabular}{|c|c|c|c|c|c|}
\hline $\begin{array}{l}\text { Concentration } \\
\text { of alcohol } \\
(\%, \mathrm{v} / \mathrm{v})\end{array}$ & $\begin{array}{l}\text { NPs ZnO } \\
\text { concentration } \\
(\mathrm{mg} / \mathrm{L})\end{array}$ & $\begin{array}{l}\text { Specific rate of } \beta- \\
\text { glucans content }(\% \\
\text { dry.weight. })\end{array}$ & $\begin{array}{l}\text { Specific rate of dry } \\
\text { biomass content, g/L }\end{array}$ & \multicolumn{2}{|l|}{$\begin{array}{l}\text { Content of } \beta- \\
\text { glucans }\end{array}$} \\
\hline 0 & 0 & $18.8 \pm 1.4$ & $5.37 \pm 0.45$ & 1.01 & g/L control \\
\hline 2 & 0 & $20.01 \pm 3.4$ & $6.06 \pm 1.3$ & 1.21 & 119.8 \\
\hline 5 & 0 & $20.86 \pm 5.5$ & $5.52 \pm 0.9$ & 1.15 & 113.8 \\
\hline 10 & 0 & $21.0 \pm 1.6$ & $1.55 \pm 0.3$ & 0.32 & 31.7 \\
\hline 0 & 5 & $20.52 \pm 1.0$ & $6.02 \pm 0.08$ & 1.23 & 121.7 \\
\hline 0 & 10 & $19.14 \pm 0.17$ & $\mathbf{6 . 1 6} \pm \mathbf{0 . 2 8}$ & 1.18 & 116.8 \\
\hline 0 & 15 & $18.78 \pm 109$ & $6.02 \pm 0.18$ & 1.13 & 111.0 \\
\hline 2 & 5 & $\mathbf{2 2 . 5 5} \pm \mathbf{1 . 9}$ & $5.88 \pm 1.2$ & $\mathbf{1 . 3 2}$ & $\mathbf{1 3 0 . 7}$ \\
\hline 2 & 10 & $21.28 \pm 1.9$ & $5.81 \pm 1.5$ & 1.24 & 122.7 \\
\hline 2 & 15 & $21.25 \pm 2.4$ & $5.74 \pm 1.3$ & 1.21 & 119.8 \\
\hline 5 & 5 & $19.5 \pm 1.9$ & $5.08 \pm 2.4$ & 0.99 & 98.0 \\
\hline 5 & 10 & $21.08 \pm 2.5$ & $4.4 \pm 2.1$ & 0.92 & 91.1 \\
\hline 5 & 15 & $19.32 \pm 2.3$ & $4.65 \pm 2.3$ & 0.89 & 88.1 \\
\hline
\end{tabular}

Analysing the experiments results, a new process for the direct $\beta$-glucan synthesis is recommended, which consists in adding to the YPD nutrient medium $5 \mathrm{mg} / \mathrm{L}$ of $\mathrm{ZnO}$

\section{CONCLUSIONS}

1. Alcohol in 2\%, 5\% and $10 \%$ concentrations added to the cultivation medium of Saccharomyces cerevisiae CNMNY-20 yeast strain stimulates carbohydrates biosynthesis, including $\beta$-glucans and, at the same time, inhibits protein synthesis. Adaptive response of yeast strain to the presence of alcohol in $10 \%$ concentration is manifested by the decrease of cellular biomass with $71 \%$, compared to control.

2. $\mathrm{ZnO}$ nanoparticles in presence of $2 \%$ and $5 \%$ alcohol concentrations stimulate processes of carbohydrates and $\beta$-glucans biosynthesis, their content in Saccharomyces cerevisiae CNMN-Y-20 biomass being with nanoparticles in combination with the alcohol in a $2 \%$ volume. Application of the process allows to obtain $1.32 \mathrm{~g} / \mathrm{L} \beta$-glucans, which are with $30.7 \%$ more than control.

\section{REFERENCES}

1. Aebi, H. (1984). Catalase in Vitro. In: Methods in Enzymology, 105, 121-126.

2. Aguilar-Uscanga, B., Francois, J.M. (2003). A study of the yeast cell wall composition and structure in response to growth conditions and mode of cultivation. Letters in Applied Microbiology, 37, 268-274. 
3. Ban, D. K., Subhankar, P. (2014). Zinc Oxide Nanoparticles Modulates the Production of $\beta$ Glucosidase and Protects its Functional State Under Alcoholic Condition in Saccharomyces cerevisiae. Appl. Biochem Biotechnol., 173, 155-166. DOI 10.1007/s12010-014-0825-2.

4. Chiseliţa, O., Usatîi, A., Taran, N., Rudic, V., Chiseliţa, N., Adajuc, V. (2010). Tulpină de drojdie Saccharomyces cerevisiae - sursă de $\beta$-glucani. Brevet de invenţie MD 4048. MD-BOPI, 6/2010.

5. Dey P., Harborn, J. (1993). Methods in Plant Biochemistry. Carbohydr. Academic Press, 2, $529 \mathrm{p}$

6. Efremova, N., Usatîi, A., Molodoi, E. (2013). Metodă de determinare a activităţii catalazei. Brevet de invenţie MD 4205, MD- BOPI, 2/2013.

7. Egorova, E., Kubatiev, A., Schvets, V. (2016). Biological Effects of Metal Nanoparticles. Springer International Publishing, 292 p. ISBN: 978-3-319-30905-7.

8. Espitia, P. J. P., Nilda de Fátima Ferreira Soares, Jane Sélia dos Reis Coimbra, Nélio José de Andrade, Renato Souza Cruz, Eber Antonio Alves Medeiros. (2012). Zinc Oxide Nanoparticles: Synthesis, Antimicrobial Activity and Food Packaging Applications. Food Bioprocess Technol., 5, 1447-1464. DOI 10.1007/s11947-012-0797-6.

9. FDA. (1997). Substances generally recognized as safe, Federal Register 62 FR 18938, April 1997

10. Gutul, T., Rusu, E., Condur, N., Ursaki, V., Goncearenco, E., Vlazan, P. (2014). Preparation of poly(N-vinylpyrrolidone)-stabilized $\mathrm{ZnO}$ colloid nanoparticles. Beilstein J. Nanotechnol., 5, $402-$ 406. doi:10.3762/bjnano.5.47.

11. Kwiatkowski S., Kwiatkowski S.E. (2012). Yeast (Sacch. cerevisiae) glucan polysaccharides: occurrence, separation and application in food, feed and health industries. In: D.N. Karunaratne (ed.) The complex world of polysaccharides. Tech Publ., Rijeka, Croatia, 47-70.

12. Liu Hong-Zhi, Qiang Wang, Yuan-Yuan Liu, and Fang Fang. (2009). Statistical optimization of culture media and conditions for production of mannan by S. cerevisiae. Biotech. and Bioprocess Engineering, 14, 577-583. DOI/10.1007/s12257-008-0248-4.

13. Lowry, O., Rosebough, N., Farr, A. et al. (1951). Protein measurment with the folin phenol reagent. J. Biol. Chem., 193, 265-275.

14. Padrova1, K., Čejkova1, A., Cajthaml, T., Kolouchova1, I., Vitova, M., Sigler, K., ̌̌ezanka, T. (2016). Enhancing the lipid productivity of yeasts with trace concentrations of iron nanoparticles. Folia Microbiol (Praha), 61(4), 329-335. Doi: 10.1007/s12223-015-0442-7.

15. Rai, M., Yadav, A., Gade, A. (2009). Silver nanoparticles as a new generation of antimicrobials. Biotechnology Advances, 27(1), 76-83.

16. Roselli M., Finamore A., Garaguso I., Britti M. S., Mengheri E. (2003). Zinc oxide protects cultured enterocytes from the damage induced by E. coli. J. of Nutrition, 133(12), 4077-4082.

17. Santimano, M. C., Kowshik, M. (2013). Altered growth and enzyme expression profile of ZnO nanoparticles exposed non-target environmentally beneficial bacteria. Environ Monit Assess, 185, 7205-7214. DOI 10.1007/s10661-013-3094-6.

18. Sawai, J. (2003). Quantitative evaluation of antibacterial activities of metallic oxide powders $(\mathrm{ZnO}, \mathrm{MgO}$ and $\mathrm{CaO}$ ) by conductimetric assay. J.of Microbiological Methods, 54(2), 177-182.

19. Sirbu, T., Maslobrod, S. N., Mirgorod, Yu. A., Borodina, V. G., Borsch, N. A., Ageeva, L. S. (2015). Influence of Dispersed Solutions of Copper, Silver, Bismuth and Zinc Oxide Nanoparticles on Growth and Catalase Activity of Penicillium funiculosum. 3rd International Conference on Nanotechnologies and Biomedical Engineering. September 23-26, 2015, Chisinau, Republic of Moldova, Volume 55 of the series IFMBE Proceedings, 55, 271-274

20. Thammakiti, S.; Suphantharika, M.; Phaesuwan, T.; Verduyn. (2004). Preparation of spent brewer's yeast $\beta$-glucans for potential applications in the food industry. International Journal of Food Science\&Technology, 39(1), 21-29.

21. Zechner-Krpan, V., Petravic-Tominac, V., Panjkota-Krbavicic, I., Grba, S. Berkovic, K. (2009). Potential application of yeast B-glucans in food industry, Agriculturae Conspectus Scientificus, 74(4), 277-282. 